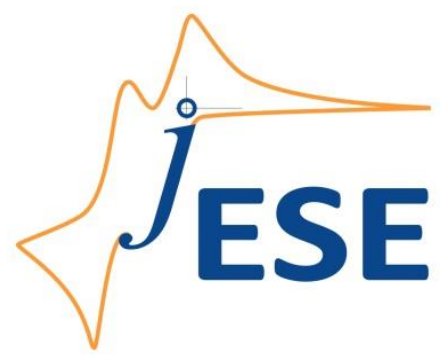

Open Access : : ISSN 1847-9286

www.jESE-online.org

Short Communication

\title{
Studying the electrochemical deposition process of molybdenum from aqueous solution of molybdate ions
}

\author{
Samira Fikret Cafarova, Akif Shikhan Aliyev, Mahmoud Elrouby*, ${ }^{*}$, Nsh Soltanova, \\ Dilgam Babir Tagiyev \\ Institute of Catalysis and Inorganic Chemistry, National Academy of sciences of Azerbaijan, \\ AZ 1143 Baku, Azerbaijan \\ *Chemistry Department, Faculty of Science, Sohag University, 82524 Shag, Egypt \\ ${ }^{\square}$ Corresponding Author: dr mahmoudelrouby@hotmail.com; Tel.: +2-011-43909358; Fax: +2-093-4601159
}

Received: September 14, 2015; Revised: December 13, 2015; Accepted: December 17, 2015

\begin{abstract}
In this study, the tracing of the electroreduction process of molybdate ions in aqueous media at different conditions is achieved for obtaining molybdenum metal in a simple and easy way. The kinetics and the mechanism of the electroreduction of molybdate ions are studied using cathodic polarization technique. It is observed that, the speed of the electroreduction process depends on the speed of the change of the cathodic potential sweep as well as on the temperature of the electrodeposition bath. Moreover, it is observed that, at the potential range from the stationary potential $\left(E_{s t}=0.25 \mathrm{~V}\right)$ to $-0.7 \mathrm{~V}$, the electroreduction of molybdate ions occurs into two steps. Moreover it is observed that, after $-0.7 \mathrm{~V}$ the electroreduction process of molybdate is accompanying with evolution of hydrogen.
\end{abstract}

\section{Keywords}

Molybdate in aqueous media; Electrochemical behavior; Platinum substrate; Cathodic polarization

\section{Introduction}

Molybdenum and its compounds are used in a wide range of different fields of industry. Molybdenum sulfide occupies a good and important position among the molybdenum compounds. $\mathrm{MoS}_{2}$ has a good crystalline structure and other physical properties such as high greasy character in high temperature and oxidation environment, stability, semi-conductivity $\left(E_{\mathrm{g}}=1.7 \mathrm{eV}\right)$ and diamagnetic properties, these features make it a significantly candidate in many industrial applications and scientific research works, such as "oily substances" and effective photoelectrodes [1]. $\mathrm{MoS}_{2}$ in its crystalline structure is observed "in sliding" shapes [2], this makes it 
suitable for the using as a good lubricant material. Also, $\mathrm{MoSe}_{2}$ has been found to be highly stable against photo-corrosion due to the $d$ - $d$ transitions and has a band gap of about $1.4 \mathrm{eV}$. Thus, it possesses a high potential towards photoelectric applications [3]. The $\mathrm{MoS}_{2}$ can be synthesized by various methods depending on the application area. Therefore, to get $\mathrm{MoS}_{2}$ thin layer it is preferred to use the electrochemical method [1]. In this method by using inexpensive equipments one can get thin layers with bigger surface area and the easiness to manage the synthesizing process. The synthesis of $\mathrm{MoS}_{2}$ thin layers as photoelectrode material using the electrochemical method in different solutions were investigated [4-5]. It should be noted that, the kinetics and mechanism of this process, the structure of the film, optical properties were not thoroughly investigated. For investigation the process of electrochemical synthesis of $\mathrm{MoS}_{2}$ thin film from aqueous solutions, at first it should be clarified kinetics and mechanism of the deposition process of the combination of the two components (Mo and $\mathrm{S}$ ) from aqueous solutions on the cathode. The kinetics of the mechanism of the electrodeposition process of sulphid from sulphite and thiosulphate were thoroughly investigated [6-8].

The electroreduction process of molybdenum ions to molybdenum on the cathode from different solutions were investigated by a number of researchers and the obtained results are different depending on the composition of the solution and the terms of the electrolysis process [9-12]. There is no sufficient information in the previous works about the kinetics and the mechanism of the electroreduction and the electrodeposition processes of the molybdate ions to molybdenum metal. In this regard, in this article the kinetics and the mechanism of the electrochemical reduction process of sodium molybdate from aqueous solution has been studied and investigated.

\section{Experimental}

All of the electrochemical experiments were carried out in a three electrodes electrochemical cell. This electrochemical cell allows the adding sample from the electrolyte, adjusting the desired temperature of the electrolyte and passing a variety of gases through the electrolyte. For adjusting the temperature in the cell and for mixing the solutions, the UTU-4 universal "ultra thermostat" and ALPHA magnetic mixer were used. Silver/silver chloride $(\mathrm{Ag} / \mathrm{AgCl} / \mathrm{KCl})$ and platinum plaques were used as reference and auxiliary electrodes, respectively. Before starting the experiment, the working electrode should be washed in a solution containing $1: 1 \mathrm{H}_{2} \mathrm{SO}_{4}$ and $\mathrm{H}_{2} \mathrm{O}_{2}$, then with the deionized water.

Cathodic polarization curves were recorded with "Iviumstat Electrochemical Interface" potentiostat equipped with a computer. Pure and grade chemicals for analysis were used, as brand sodium molybdate. The deionized water was used for preparing the solutions and electrolytes without further purification.

\section{Results and discussion}

The kinetics and the mechanism of the electroreduction of molybdate ions were studied and traced using the cathodic polarization method.

Figure 1 shows the cathodic polarization curves of $0.25 \mathrm{M} \mathrm{Na}_{2} \mathrm{MoO}_{4}$ on platinum electrode at different speed rates of potential; $1-5,2-10,3-20,4-40,5-60$ and $6-80 \mathrm{mV} / \mathrm{s}$ at $T=295 \mathrm{~K}$. As can be seen from Figure 1 the changing and the increasing of the potential sweep rate from $5 \mathrm{mV} / \mathrm{s}$ to $80 \mathrm{mV} / \mathrm{s}$ in the direction of the cathodic process leads to an increase of the cathodic current peak height. Moreover, at $-0.072 \mathrm{~V}$ the cathodic process increases about 2.93 times, at $-0.7 \vee 1.91$ times and at $-0.8 \mathrm{~V} 1.72$ times. 


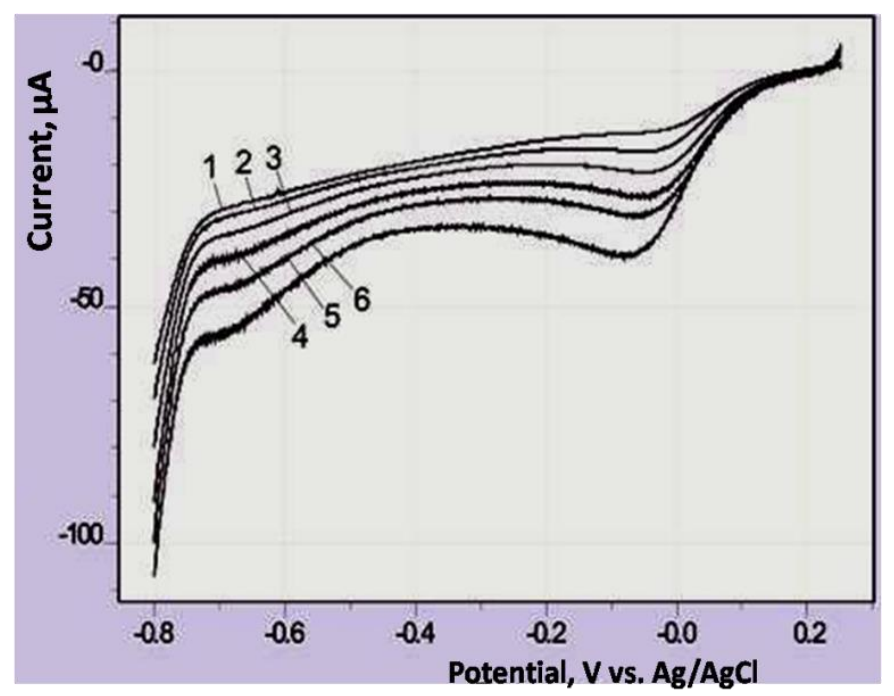

Figure 1. Cathodic polarization curves of $0.25 \mathrm{M} \mathrm{Na}_{2} \mathrm{MoO}_{4}$ on platinum electrode at different speed rates of potential: $1-5,2-10,3-20,4-40,5-60$ and $6-80 \mathrm{mV} / \mathrm{sec}$ at T=295 $\mathrm{K}$

The obtained data in Figure 2 shows the dependence of the peak current density, $i_{p}$, on the square root of the speed potential change. This dependence allows assigning the effective nature of the rate determining step in the electro-precipitation process of the metal. As seems from Figure 2 this dependence is linear and confirms that, the cathodic process is diffusion in nature at the peak of current density.

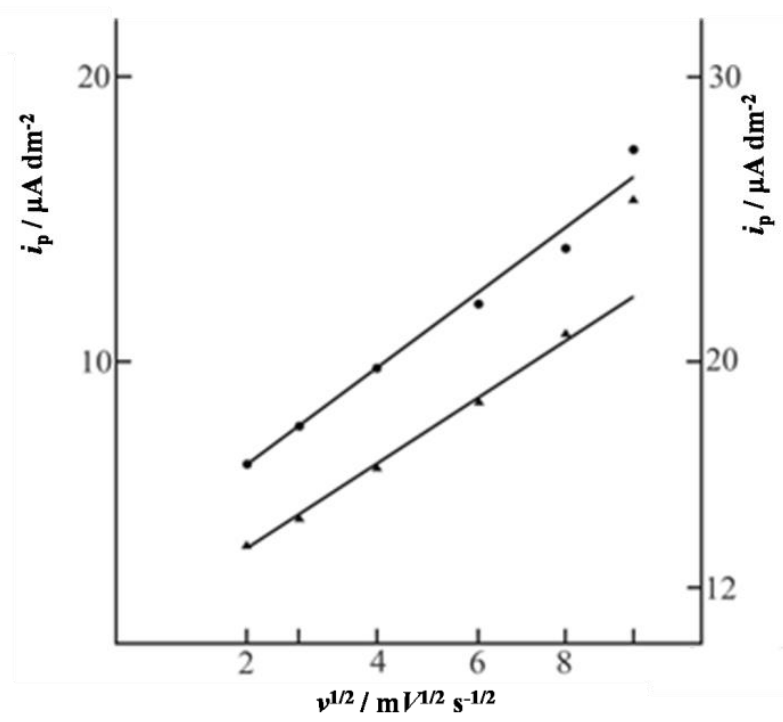

Figure 2.Dependence of the peak current density $i_{p}$ on the square root of speed change of potential $\mathrm{v}^{1 / 2}$. The composition of solution like as Figure 1.

For more information about the nature of cathodic polarization process, we need to investigate the reaction dependence on the temperature. Thus, the dependence of the speed of electroreduction of molybdate ions on temperature has been performed. For detecting the nature of cathodic polarization process, the areas around the electroreduction peaks in polarization curves at each temperature should be taken into account [13].

Investigation of the dependence of the electroreduction process of molybdate ions at the cathode on temperature illustrates that, the reduction process occurs rapidly while temperature increases. As shown from Figure 3, by increasing the temperature from 295 to $343 \mathrm{~K}$ at the 
potential of $-0.2 \mathrm{~V}$, the cathodic peak current (eletcroreduction process) increases 2.48 times and increases about 1.37 times at $-0.62 \mathrm{~V}$ potential in the cathodic process.

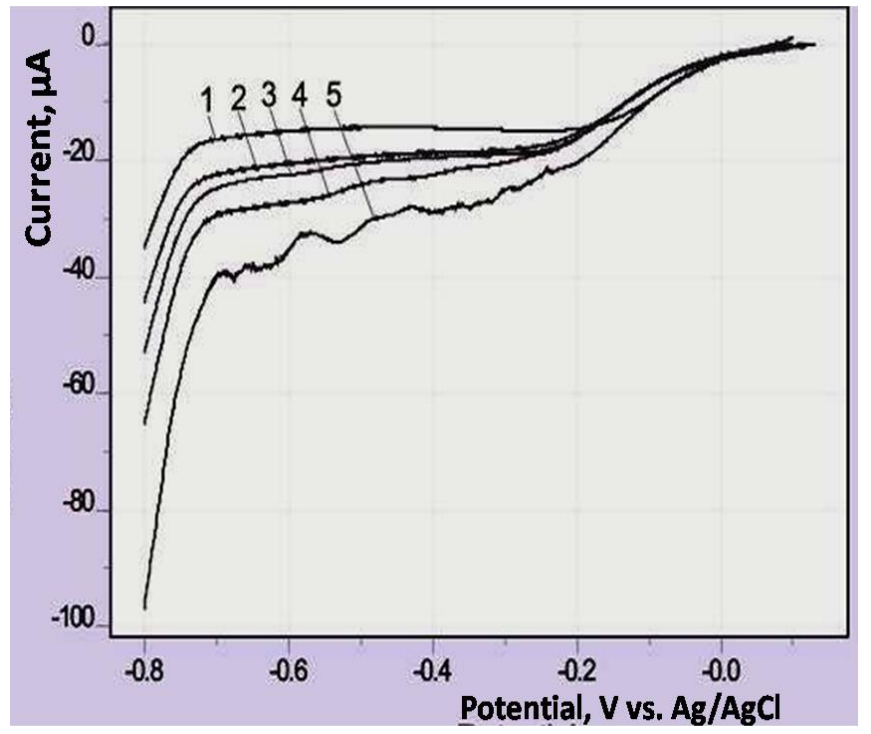

Figure 3. Cathodic polarization curves on platinum electrode of electrolyte coposition $0.25 \mathrm{M} \mathrm{Na}_{2} \mathrm{MoO}_{4}$. at different temperatures: 1 - 295; 2 - 303; 3 - 313; 4 - 323; 5 - $343 \mathrm{~K}$

The activation energy of the cathodic process was calculated based on the results given in Figure 3. For this purpose the equation $\log i_{\mathrm{k}}=$ const $-A_{\text {ef }} / 2.303 R T$ is used [14]. Where, $i_{\mathrm{k}}$ is the current density, $A_{\text {ef }}$ - the effective activation energy, $R$ - gas constant and $T$ - temperature in Kelvin. The activation energy was calculated from the coordination between $\log i_{\mathrm{k}}$ and $1 / T$, then from the slope angle of straight lines $A_{\text {ef }}$ can be determined.

As shown from Fig. 4, the dependence of the rate of the cathodic process at different potentials on the inverse of temperature is linear in character. This also confirms the diffusion control of the electroreduction process.

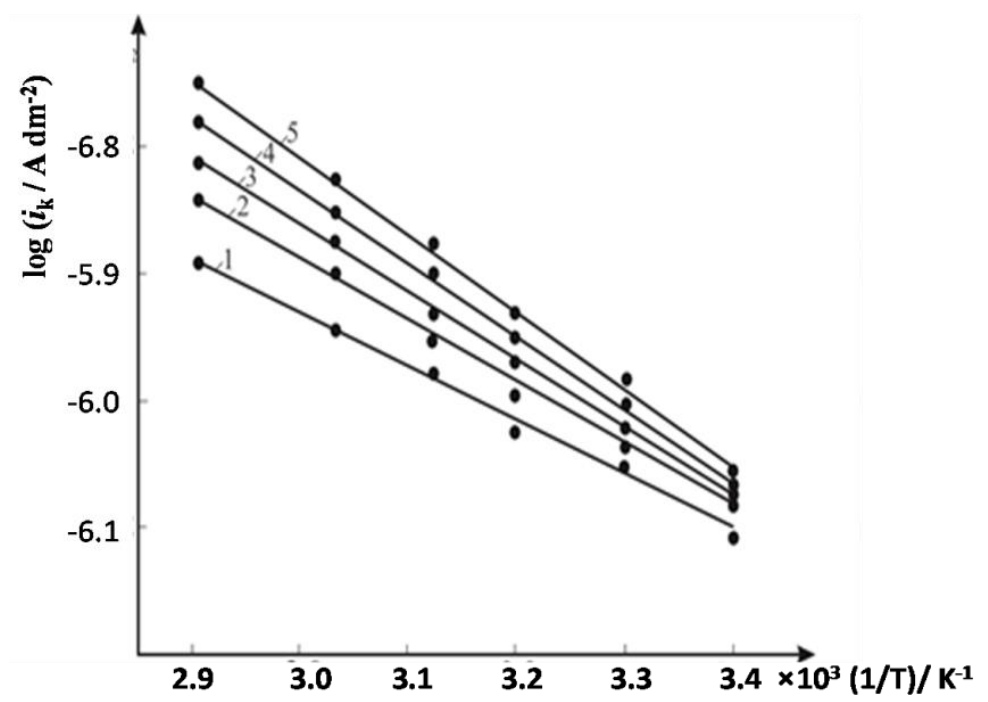

Figure 4. Dependence of logarithmic values of the cathodic current density on temperature inverse, the electrolyte consists of $-0.25 \mathrm{M} \mathrm{Na}_{2} \mathrm{MoO}_{4}$. At different selected values of potentials vs. $\mathrm{Ag} / \mathrm{AgCl} / \mathrm{KCl}_{\text {sat }}$. $1-0.2 ; 2-0.4 ; 3-0.5 ; 4-0.6 ; 5-0.7$ and $6-0.8 \mathrm{~V}$

The values of the activation energy calculated from Figure 4 relatively decrease when cathodic potential increases, where at $-0.2 \mathrm{~V}$, the $A_{\text {ef }}=37.28 \mathrm{kcal}$ and at $-0.7 \mathrm{~V} A_{\text {ef }}=36.99 \mathrm{kcal}$ at $T=295 \mathrm{~K}$ 
but at $T=343 \mathrm{~K}$, the activation energy decreased from 44.86 to $40.36 \mathrm{kcal}$. From these results, it can be concluded that the rate determining step of the cathodic process is mainly under diffusion control in character.

The mechanism of the electroreduction route of molybdate can be deduced from the previous data as follows:

$$
\begin{array}{lc}
\mathrm{MoO}_{4}{ }^{2-}+2 \mathrm{H}_{2} \mathrm{O}+2 \mathrm{e}^{-}=\mathrm{MoO}_{2}+4 \mathrm{O}^{-} & \text {at first peak } \\
\mathrm{MoO}_{2}+2 \mathrm{H}_{2} \mathrm{O}+2 \mathrm{e}^{-}=\mathrm{Mo}^{2+}+4 \mathrm{OH}^{-} & \text {at second peak } \\
\mathrm{Mo}^{2+}+2 \mathrm{e}^{-}=\mathrm{Mo} \rightarrow \text { after the second peak accompanying with hydrogen evolution. }
\end{array}
$$

\section{Conclusions}

After the tracing of the electroreduction process of molybdate ions in aqueous media at different conditions, the kinetics and the mechanism of the electroreduction were detected using cathodic polarization. It is concluded that, the speed of electroreduction process of molybdate ions at the discussed conditions is affected the speed of the change of the cathodic potential sweep as well as the temperature of electrodeposition bath. Moreover, the mechanism of the route of the electroreduction process of molybdate is detected and proposed. From the stationary potential $\left(E_{\mathrm{st}}=0.25 \mathrm{~V}\right)$ to $-0.7 \mathrm{~V}$ the reduction of molybdate ions occurs at two steps and after $-0.7 \mathrm{~V}$ the electroreduction process of molybdate is accompanying with evolution of hydrogen.

\section{References}

[1] A. Sh. Aliyev, M. Elrouby, S. F. Cafarova, Mater. Sci. Semicond. Process. 32 (2015) 31-39.

[2] P. D. Fleischaur, Thin Solid Films 154 (1987) 309-322.

[3] V. M. Pathak, K. D. Patel, R. J. Pathak, R. Srivastava, Sol. Energy Mater. Sol. Cells 73 (2002) 117-123.

[4] E. A. Ponomarev, R. Tenne, A. Katty, C. Lavy-Clement, Sol. Energy Mater. Sol. Cells 52 (1998) 125-133.

[5] T. Joseph Sahaya Anand, Sains Malays. 38 (2009) 85-89.

[6] A. Sh. Aliyev, M. Mamedov, Z. F. Gulakmedova, Proc. Georgian Acad. Sci. Chem. Series 1-2 (2006) 156-160.

[7] M. El-rouby, A. Sh. Aliyev, Casp. J. Appl. Sci. Res. 2(7) (2013) 18-25.

[8] A. Sh. Aliyev, M. El-rouby, M. T. Abbasov, A. S. Suleymanov, Nanosci. Nanotech. Inter. J. 3(3) (2013) 60-64.

[9] H. Nakajima, T. Nohira, R. Hagiwara, Electrochim Acta 51(18) (2006) 3776-3780.

[10] R. Syed, S. K. Ghosh, P.U. Sastry, G. Sharma, R. C. Hubli, J. K. Chakravartty, Surf. Coat. Technol. 261 (2015) 15-20.

[11] N. D. Ivanova, S. V. Ivanov, E. I. Boldyrev, O. A. Stadnik, Prot. Met. 42(4) (2006) 354-358.

[12] J. M. Thomas, L. Penner, P. Schaffer, J. R. Thomas, F. Bénard, E. Asselin, Electrochem. Commun. 15 (2012) 78-80.

[13] Z. Qalyus, Teoreticheskoy osnovy elektrokhimicheskogo analiza [theoretical bases of the electrochemical analysis] 1974, Mir, Moscow, Russia, 212 [in Russian]

[14] S. V. Qorbakhev, Fizicheskoy Khimii Zhurnal [journal of physical chemistry] 24(7) (1950) 888896. [in Russian]

(C) 2015 by the authors; licensee IAPC, Zagreb, Croatia. This article is an open-access article distributed under the terms and conditions of the Creative Commons Attribution license

(http://creativecommons.org/licenses/by/4.0/) (cc) Er 